\title{
Similar pulmonary functional outcomes at 3 months in critical COVID-19 survivors hospitalized during the first, second, and third pandemic waves
}

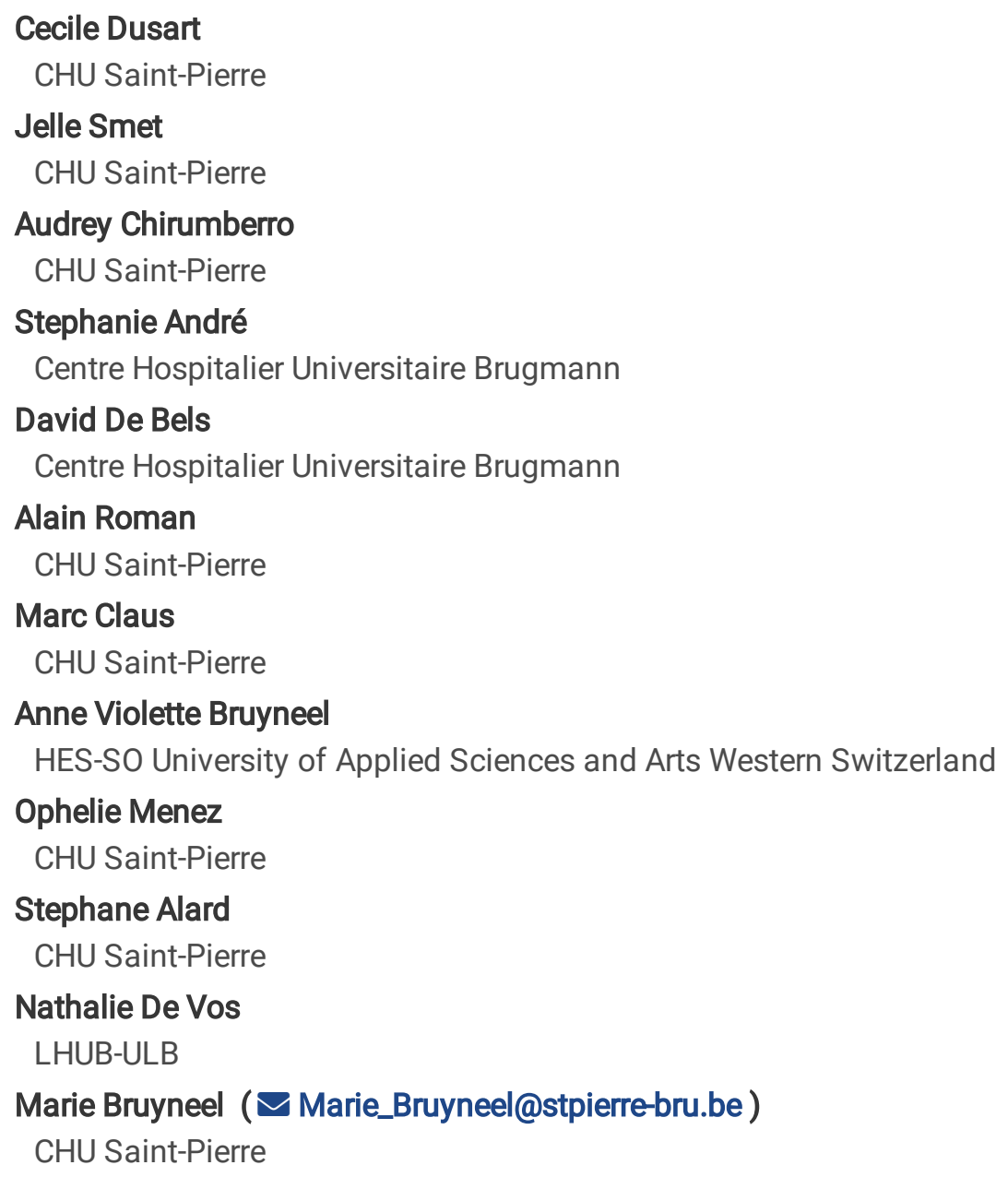

\section{Research Article}

Keywords: COVID-19, ARDS, Chest CT, pulmonary function test, intensive care unit, quality of life, pandemic, wave, mortality

Posted Date: February 25th, 2022

DOI: https://doi.org/10.21203/rs.3.rs-1384691/v1

License: @ (i) This work is licensed under a Creative Commons Attribution 4.0 International License. Read Full License 


\section{Abstract}

Introduction

Despite improvements in the management of COVID-19 patients, we still don't know whether pharmacological treatments and improvements in ventilatory support have changed outcomes for intensive care unit (ICU) survivors of the three consecutive waves $(w)$ of the pandemic. The objective of this study was to assess pulmonary functional outcomes, radiologic pattern, and quality of life (QoL) in ICU COVID-19 survivors at 3 months, according to pandemic wave.

Methods

All patients admitted to the ICU for COVID-19 acute respiratory distress syndrome (ARDS) at two university hospitals were prospectively included and assessed 3 months post-ICU discharge by chest CT, pulmonary function test (PFT), 6-minute walking distance test (6MWDT), respiratory muscle strength (RMS) test, and Short Form 36 (SF-36) questionnaire.

Results

Eighty-four ARDS COVID-19 survivors were included. Hospital length of stay was shorter during w3 vs w1 (23.4 \pm 14.2 days vs $34.7 \pm 20.8$ days, $p=0.03)$. Fewer patients required mechanical ventilation (MV) during w2 vs $w 1(33.3 \%$ vs $63.9 \%, p=0.0038)$. Three months after ICU discharge, PFT, 6MWDT, and RMS were similar, regardless of wave ( $>0.05)$. QoL (SF-36) was worse for patients in w1 vs w3 $(64.7 \pm 16.3$ vs $49.2 \pm 23.2, p=0.0169)$.

On linear/logistic regression analysis, MV was associated with decreased TLC, FEV1, DLCO, and RMS (w1,2,3, p<0.05). Low SF-36 score was correlated with low 6MWDT (w3, $p=0.01)$. The use of glucocorticoids was associated with better TLC, FEV1, DLCO, and number of affected segments on chest CT $(p=0.0001)$, and tocilizumab was associated with higher TLC $(p=$ 0.027). Remdesevir improved MV duration in wave $2(p=0.008)$.

Conclusions

Despite better understanding and management of COVID-19, PFT, 6MWDT, and RMS remained similar in ICU survivors, regardless of the pandemic wave in which they were hospitalized.

\section{Introduction}

Coronavirus disease 2019 (COVID-19) is the third and most important outbreak of coronavirus this century. This outbreak was recognized as a pandemic by the World Health Organization on the 11th of March, 2020. As of the 28th of January, 2022, among a total population of approximately 364 million inhabitants who have contracted SARS coronavirus-2 (SARS-CoV-2), more than 5.63 million people have died worldwide [1]. The number of patients affected by SARS-CoV-2 is still rising, with striking problems related to emerging variants of concern (VOC), despite vaccination rates of up to $84 \%$ in European countries [2].

The spectrum of disease is broad, with $5 \%$ of symptomatic COVID-19 patients suffering from severe respiratory failure, fulfilling the Berlin definition of acute respiratory distress syndrome (ARDS), requiring intensive care unit (ICU) admission [3, 4]. Despite the development of a panel of treatments that have shown efficacy for improving patient outcomes and reducing mortality (e.g. anti-coagulation, glucocorticoids (GC), anti-viral therapies, monoclonal antibodies, ventilatory support) [5, 6], we still face, in ICU-admitted patients, multiorgan acute complications related to SARS-CoV-2 infection (renal, hepatic, thromboembolic, neurologic, cardiac, muscular). These may be directly attributable to the virus, such as immune-mediated mechanisms or microangiopathy, or indirect challenges related to subsequent long hospital stays, bed rest, iatrogenic factors, or psychological disorders [7-9]. The 6-minute walking distance test (6MWDT) is a good test to capture post COVID-19 disability, assessing both muscle dysfunction and ventilatory limitation. It has been shown to be reduced in 65\% of ICU COVID19 patients 3 months after discharge [10]. We do not know yet whether the present management of ICU COVID-19 patients has changed long-term outcomes compared to patients who were initially affected at the start of the pandemic.

Page $2 / 11$ 
The aim of the present study was to assess outcomes in ICU COVID-19 survivors 3 months after ICU discharge, according to the timing of hospitalization (1st, 2nd, and 3rd pandemic waves). The primary outcome was to assess the percentage of patients who exhibited an impaired walking distance, below $80 \%$, during the 6-minute walking distance test (6MWDT), 3 months after ICU discharge. Secondary outcomes included comparisons of pulmonary function tests, quality of life, and radiologic impairment 3 months after ICU discharge. Impact of COVID specific treatments was also assessed.

\section{Methods}

\section{Design}

This was a prospective observational and multicentric study. Patients admitted to intensive care or fulfilling the Berlin criteria for COVID-19 related ARDS at CHU Saint Pierre and CHU Brugmann (tertiary reference hospitals) were included in the study.

\section{Patients}

Adult patients were included at 3 months from ICU discharge and assessed by chest computed tomography (CT), lung function tests, and questionnaires. Exclusion criteria included language barrier, refusal, and psychiatric or mental disorders.

All included patients provided written informed consent to participate in the study. The study protocol was approved by the Saint-Pierre University Hospital ethics committee (AK/16-01-18/4613) and by the Brugmann University Hospital ethics committee (CE2020/141). All procedures performed in studies involving human participants were in accordance with the ethical standards of the institutional and/or national research committee and with the 1964 Helsinki declaration and its later amendments or comparable ethical standards.

\section{Data collection}

\section{Baseline data}

Data related to hospitalization were collected from the medical files of the patients, including demographics, APACHE II score, Sequential Organ Failure Assessment (SOFA) score at ICU admission, biological data, COVID-19 treatments, and complications.

The first COVID-19 pandemic wave (w1) refers to ICU admission between March 1, 2020 and October 9, 2020, the second wave (w2) was between October 10, 2020 and March 14, 2021, and the third wave (w3) was between March 15, 2021 and June 30, 2021.

\section{3-month assessment}

A comprehensive assessment of patients was performed 3 months after ICU discharge, according to a procedure previously described in Truffaut et al. [10]. Assessments included Chest CT, pulmonary function test (PFT), 6MWDT with continuous Sp02 monitoring, respiratory muscle strength (RMS) measurements, and three questionnaires: Quality of life (QoL) using the Short Form 36 (SF-36), Breathlessness using the modified Medical Research Council dyspnea scale (mMRC), and post-COVID disability using the post-COVID Functional Status (PCFS) test [11].

\section{Statistical analysis}

The statistical data treatment included descriptive statistics. Qualitative data are expressed as frequencies and percentages. For quantitative data, the mean and standard deviation were calculated.

The demographic, clinical characteristics and clinical outcomes were compared between the three waves (w1 vs. w2 vs. w3) for demographic and clinical characteristics. Normality and homoscedasticity were assessed with Shapiro's test and Levene's test, respectively, for quantitative variables. In case of data with a normal distribution, a one-way ANOVA was calculated. For pairwise comparisons, a Bonferroni post-hoc test was applied. In cases where the data were not normally distributed, the non- 
parametric Kruskal Wallis test was used with a Dunn post-hoc test. The comparison between the three waves for qualitative data was tested with the Marascuilo procedure. The Marascuilo procedure was used to compare proportions when there were more than two groups with binary outcomes (yes/no). This is initially used to perform a test of overall homogeneity for a large contingency table, using the standard Chi Square Test. This is followed by multiple post-hoc comparisons between pairs of groups in the data.

The evolution of the scanner results was compared between waves (w1 vs. w2 vs. w3). The delta (three-month value baseline value) was calculated for each subject. Next, the delta values were compared between waves with the one-way ANOVA and Bonferroni post-hoc test.

To compare the patients with and without medication (Remdevisir or Tocilizumab) or thromboembolic events for demographic and clinical variables, the one-way ANOVA or Mann Whitney $U$ tests were applied in accordance with the normality of the distribution.

For each wave, the predictive factors of the 3-month clinical outcomes were assessed. A multiple linear or logistic regression analysis (according to data type) was used to determine the variables that had the greatest influence.

A p-value below 0.05 was considered as statistically significant. All analyses were performed using python (version 3.8) with the statistics package statsmodels (version 0.11.1). The package is released under the open source modified BSD (3-clause) license.

\section{Results}

Eighty-four ARDS survivors of the first three COVID-19 pandemic waves were included in the study (Fig. 1). The ICU mortality rate was not different between $w 1$ and $w 2(29 \%$ and $36 \%, p=0.29)$ but was significantly lower during w3 vs w1 (18\% vs $29 \%, p$ $=0.05)$ and vs w2 $(18 \%$ vs $36 \%, p=0.0002)$. Demographics and clinical data for the 84 included patients are summarized in Table 1. 
Table 1

Baseline characteristics of patients, according to wave of the pandemic

\begin{tabular}{|c|c|c|c|c|c|c|c|}
\hline $\begin{array}{l}\text { Variables } \\
\text { (mean, SD or } \mathrm{n} \\
(\%)\end{array}$ & $\begin{array}{l}\text { Wave } 1 \\
n=36\end{array}$ & Wave $2 \mathrm{n}=27$ & Wave $3 n=21$ & $\begin{array}{l}\text { P value } \\
\text { (Anova or } \\
\text { Kruskal } \\
\text { Wallis tests) }\end{array}$ & $\begin{array}{l}\text { p value } \\
\text { (wave } 1 \text { vs. } \\
\text { wave } 2 \text { ) }\end{array}$ & $\begin{array}{l}\text { p value } \\
\text { (wave } 1 \text { vs. } \\
\text { wave } 3 \text { ) }\end{array}$ & $\begin{array}{l}p \\
\text { value } \\
\text { (wave } \\
2 \text { vs. } \\
\text { wave } \\
3 \text { ) }\end{array}$ \\
\hline Age & $\begin{array}{l}56.64 \pm \\
10.33\end{array}$ & $59.48 \pm 10.92$ & $53.1 \pm 13.06$ & 0.1555 & 0.8868 & 0.7876 & 0.2146 \\
\hline Sex, female & $\begin{array}{l}8 \\
(22.2 \%)\end{array}$ & $11(14.7 \%)$ & 12 (57.1\%) & 0.0274 & 0.2872 & 0.0246 & 0.5205 \\
\hline non obese & $\begin{array}{l}14 \\
(38.9 \%)\end{array}$ & 13 (48.15\%) & $11(52.38 \%)$ & 0.5739 & 0.7630 & 0.6111 & 0.9585 \\
\hline active smokers & $\begin{array}{l}3 \\
(8.33 \%)\end{array}$ & 20 (74.07\%) & $1(4.76 \%)$ & 0.6047 & 0.6814 & 0.9889 & 0.6679 \\
\hline \multirow{6}{*}{$\begin{array}{l}\text { Medical history } \\
\text { cancer } \\
\text { diabetes } \\
\text { hypertension } \\
\text { HIV }\end{array}$} & \multirow{2}{*}{$\begin{array}{l}1 \\
(2.78 \%)\end{array}$} & $1(3.70 \%)$ & $1(2.78 \%)$ & 0.9261 & 0.9795 & 0.9346 & 0.9840 \\
\hline & & 15 (55.56\%) & 8 (38.10\%) & 0.4111 & 0.5451 & 0.9652 & 0.4732 \\
\hline & (41.67\%) & 17 (62.96\%) & $10(47.62 \%)$ & 0.5677 & 0.8377 & 0.8453 & 0.5634 \\
\hline & $\begin{array}{l}20 \\
(55.56 \%)\end{array}$ & 0 & 0 & $\mathrm{~N} / \mathrm{A}$ & 0.1974 & 0.7258 & 0.7318 \\
\hline & $\begin{array}{l}2 \\
(5.56 \%)\end{array}$ & $1(3.70 \%)$ & $2(9.52 \%)$ & 0.2526 & & & \\
\hline & $\begin{array}{l}6 \\
(16.67 \%)\end{array}$ & & & & & & \\
\hline OSA & & & & & & & \\
\hline $\begin{array}{l}\text { Length of stay } \\
\text { (days) }\end{array}$ & $\begin{array}{l}34.72 \pm \\
20.76\end{array}$ & $\begin{array}{l}27.81 \pm \\
16.93\end{array}$ & \pm 14.25 & & & & \\
\hline $\begin{array}{l}\text { Hospital } \\
\text { ICU }\end{array}$ & $\begin{array}{l}20.5 \pm \\
15.97\end{array}$ & $\begin{array}{l}15.04 \pm \\
14.03\end{array}$ & \pm 11.72 & & & & \\
\hline $\begin{array}{l}\text { ICU severity } \\
\text { scores }\end{array}$ & $\begin{array}{l}10.06 \pm \\
4.05\end{array}$ & $\begin{array}{l}9.04 \pm \\
4.82\end{array}$ & \pm 5.02 & 0.1 & & & 47 \\
\hline $\begin{array}{l}\text { APACHE } \\
\text { SOFA }\end{array}$ & $\begin{array}{l}3.67 \pm \\
2.29\end{array}$ & $\begin{array}{l}3.11 \pm \\
1.25\end{array}$ & +1.69 & 0.6 & & & \\
\hline
\end{tabular}

ICU: intensive care unit, ECMO: extracorporal membranous oxygenation ; OSA, obstructive sleep apnea 


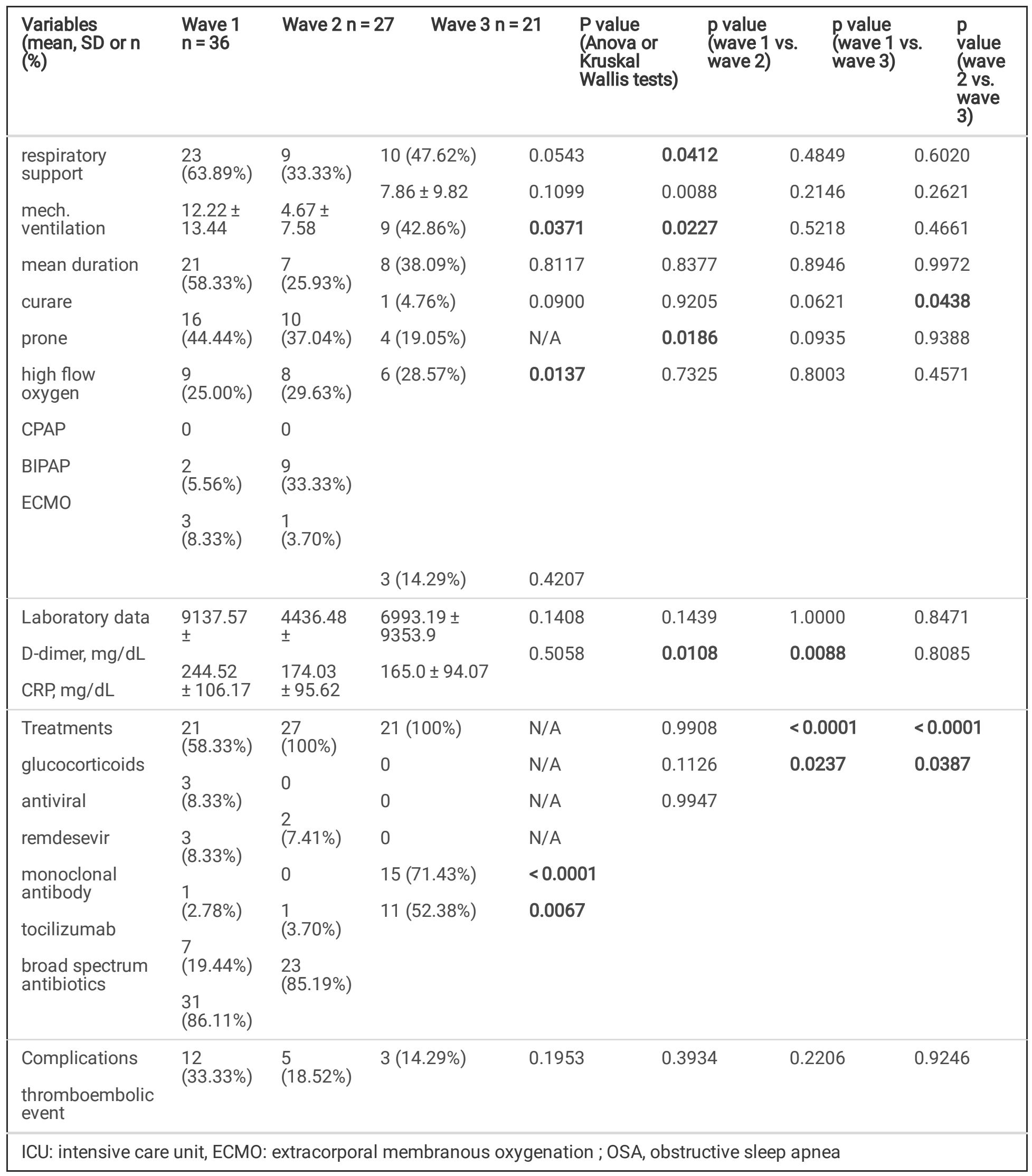

Mean hospital length of stay was shorter during w3 vs w1 (23.4 \pm 14.2 days vs $34.7 \pm 20.8$ days, $p=0.03)$. Fewer patients required mechanical ventilation (MV) during w2 vs w1 (33.3\% vs $63.9 \%, p=0.0038)$, such that the use of curare was also reduced $(p=0.0227)$. The use of tocilizumab increased significantly during $w 3(71.4 \%$ vs $19.4 \%$ for $w 1, p<0.0001$ and vs $3.7 \%$ for $w 2, p<0.0001$ ) while broad-spectrum antibiotic use decreased. 
Three months after ICU discharge, no differences in the number of patients exhibiting impairment in the 6MWDT $(<80 \%)$ were observed between waves. The results of PFTs, RMS tests, and 6MWDTs were similar overall, regardless of the wave. Quality of life, assessed by the SF-36, was worse in the vitality and mental health items for patients from w1 vs w3 (total scores $64.7 \pm$ 16.3 vs $49.2 \pm 23.2, p=0.0169)$. These results are summarized in Table 2 .

Table 2

Comparisons of clinical outcomes between waves

\begin{tabular}{|c|c|c|c|c|c|c|c|}
\hline $\begin{array}{l}\text { Variables (mean, } \\
\text { SD or \%) }\end{array}$ & Wave 1 & Wave 2 & Wave 3 & $\begin{array}{l}\text { P value (Anova or } \\
\text { K.Wallis) }\end{array}$ & $\begin{array}{l}p(w 1 \text { vs. } \\
w 2)\end{array}$ & $\begin{array}{l}p(w 1 \text { vs. } \\
\text { w3) }\end{array}$ & $\begin{array}{l}p(w 2 \text { vs. } \\
\text { w3) }\end{array}$ \\
\hline PFT & & $2.47 \pm 0.82$ & & 0.0096 & 0.1230 & 0.0094 & 1.0 \\
\hline FEV1 (L) & \multirow{2}{*}{$\begin{array}{l}87.92 \pm \\
14.71\end{array}$} & $79.81 \pm$ & & 0.1056 & 0.2315 & 0.1489 & 1.0 \\
\hline FEV1 (\%) & & 21.06 & $\begin{array}{l}79.19 \pm \\
17.67\end{array}$ & 0.0322 & 0.1466 & 0.0443 & 1.0 \\
\hline FVC (L) & \multirow{2}{*}{$\begin{array}{l}3.41 \pm \\
0.83\end{array}$} & $7152+$ & \multirow{2}{*}{$\begin{array}{l}2.8 \pm 0.94 \\
78.33 \pm \\
18.25\end{array}$} & 0.2299 & 0.2585 & 1.0 & 1.0 \\
\hline FVC (\%) & & 19.58 & & 0.2218 & 0.8973 & 0.9969 & 0.9130 \\
\hline FEV1/FCV & $\begin{array}{l}82.28 \pm \\
15.73\end{array}$ & $0.83 \pm 0.08$ & \multirow[b]{2}{*}{$\begin{array}{l}0.82 \pm 0.1 \\
75.35 \pm \\
22.34\end{array}$} & 0.6118 & 1.0 & 0.9340 & 1.0 \\
\hline DLCO (\%) & $\begin{array}{l}0.83 \pm \\
0.07 \\
81.12 \pm \\
18.32\end{array}$ & $\begin{array}{l}78.24 \pm \\
22.23\end{array}$ & & & & & \\
\hline \multirow{5}{*}{$\begin{array}{l}\text { 6MWDT } \\
\text { distance }(\mathrm{m}) \\
\text { distance }(\%) \\
\text { distance < } 80 \% \\
\begin{array}{l}\text { oxygen } \\
\text { desaturation }\end{array}\end{array}$} & \multirow{2}{*}{$\begin{array}{l}500.18 \pm \\
89.07\end{array}$} & \multirow{2}{*}{$\begin{array}{l}417.71 \pm \\
132.89\end{array}$} & \multirow{2}{*}{$\begin{array}{l}434.1 \pm \\
109.0\end{array}$} & 0.0250 & 0.0533 & 0.0596 & 1.0 \\
\hline & & & & 0.1831 & 0.2060 & 0.5454 & 1.0 \\
\hline & $\begin{array}{l}73.05 \pm \\
11.36\end{array}$ & $\begin{array}{l}83.67 \pm \\
91.36\end{array}$ & $\begin{array}{l}67.88 \pm \\
16.45\end{array}$ & 0.7904 & 0.8134 & 1.0000 & 0.8564 \\
\hline & $\begin{array}{l}n=24 \\
(66.67 \%)\end{array}$ & $\begin{array}{l}n=19 \\
(70.37 \%)\end{array}$ & $\begin{array}{l}n=14 \\
(66.67 \%)\end{array}$ & 0.7411 & 0.7331 & 0.9683 & 0.9038 \\
\hline & $\begin{array}{l}n=11 \\
(33.33 \%)\end{array}$ & $\begin{array}{l}n=6 \\
(24.00 \%)\end{array}$ & $\begin{array}{l}n=6 \\
(30.00 \%)\end{array}$ & & & & \\
\hline RMS & $89.03 \pm$ & $70.98 \pm$ & $77.81 \pm$ & 0.0931 & 0.0802 & 0.6038 & 1.0 \\
\hline $\begin{array}{l}\text { IP max (cm H20) } \\
\text { EP max (cm H20) }\end{array}$ & $\begin{array}{l}105.95 \pm \\
32.06\end{array}$ & $\begin{array}{l}87.71 \pm \\
39.09\end{array}$ & $\begin{array}{l}85.57 \pm \\
36.07\end{array}$ & 0.0637 & 0.1612 & 0.1040 & 1.0 \\
\hline mMRC & $\begin{array}{l}0.74 \pm \\
0.96\end{array}$ & $1.26 \pm 1.1$ & $1.33 \pm 1.2$ & 0.0722 & 0.1551 & 0.1399 & 1.0000 \\
\hline PCFS & $\begin{array}{l}1.31 \pm \\
1.18\end{array}$ & $1.56 \pm 1.19$ & $\begin{array}{l}1.67 \pm \\
1.43\end{array}$ & 0.7272 & 1.0 & 1.0 & 1.0 \\
\hline SF36 & $\begin{array}{l}64.71 \pm \\
16.26\end{array}$ & $\begin{array}{l}57.23 \pm \\
21.46\end{array}$ & $\begin{array}{l}49.19 \pm \\
23.24\end{array}$ & 0.0241 & 0.4004 & 0.0169 & 0.6743 \\
\hline $\begin{array}{l}\text { PFT: pulmonary fu } \\
\text { lungs for carbon } \\
\text { PCFS: post-COVID } \\
\text { EP: expiratory pres }\end{array}$ & $\begin{array}{l}\text { on test, } \\
\text { xide; } 6 \mathrm{~N} \\
\text { ctional } 5\end{array}$ & $\begin{array}{l}\text { rced expi } \\
\text {-minute } \mathrm{W} \\
\text { mMRC: } \mathrm{m}\end{array}$ & $\begin{array}{l}\text { y volume } \\
\text { ig distan } \\
\text { ied Medi }\end{array}$ & $\begin{array}{l}\text { : forced vital capa } \\
\text { st, RMS: respirator } \\
\text { esearch Council d }\end{array}$ & $\begin{array}{l}\text { DLCO: } \mathrm{d} \\
\text { scle stre } \\
\text { ea scale, }\end{array}$ & $\begin{array}{l}\text { sing capa } \\
\text { h, SF36: S } \\
\text { inspirator }\end{array}$ & $\begin{array}{l}\text { of the } \\
t \text { Form } 36 \text {, } \\
\text { ressure, }\end{array}$ \\
\hline
\end{tabular}

No differences in affected segments were observed at baseline and 3-month chest CT, but at 3 months, more patients from w2 vs w1 exhibited ground glass opacities $(41 \%$ vs $3 \%, p=0.0006)$ and fibrosis was much more frequent in w1 vs w2 $(94 \%$ vs $67 \%$, $p=0.0186)$.

The multiple linear or logistic regression analysis highlighted that for w1 patients, total lung capacity (TLC), forced expiratory volume 1 (FEV1), diffusing capacity of the lungs for carbon monoxide (DLCO), maximum inspiratory pressure (PI Max), and 
6MWDT at 3 months were correlated with mechanical ventilation (MV) and high APACHE II score (all $p<0.05$ and $p \leq 0.01$, respectively), as well as SF-36 $(p=0.006)$. The number of affected segments on 3-month CT correlated with the initial number of affected segments on chest CT scan $(p=0.04)$ and with high APACHE II score $(p=0.04)$.

For w2 patients, TLC, FEV1, DLCO, and PI Max at 3 months were correlated with MV and high SOFA score (all $p \leq 0.02$ and $p \leq$ 0.03 , respectively). SF-36 correlated with SOFA $(p=0.02)$, and PCFS with extracorporeal membrane oxygenation $(E C M O)$ duration $(p=0.03)$.

For w3 patients, TLC, FEV1, DLCO, and 6MWDT were correlated with MV ( $p \leq 0.01)$ as was SF-36 $(p=0.03)$. Low SF-36 and high PCFS scores were correlated with low 6MWDT $(p=0.01$ and 0.03$)$.

The use of glucocorticoids was associated with better TLC, FEV1, DLCO, and number of affected segments on 3-month CT (all $p<0.0001)$, and tocilizumab was associated with higher TLC $(p=0.027)(w 1)$, and with a reduction in affected segments on 3month CT ( $p=0.0065)(w 2)$. Remdesevir improved MV duration in w2 ( $p=0.0083)$.

Patients in w3 suffering from acute thromboembolic events exhibited a decreased 6MWDT $(p=0.035)$ and a higher number of affected segments on 3-month CT $(p=0.0293)$.

\section{Discussion}

This study shows that, despite progressive better understanding and management of COVID-19 patients, pulmonary functional outcomes (PFT, 6MWDT, RMS) remained similar in each pandemic wave. Disappointingly, in survivors, long-term outcomes of ICU COVID-19 did not improve during the second and third waves. However, patients from w1 exhibited more fibrosis on chest CT compared with patients from w2, a result that can be explained by a lower use of GC in w1. W1 patients also reported worse QoL in vitality and mental health items versus those in w3, a result that is probably related to supplemental factors that affected emotional well-being in w1, such as reduced access to family members during ICU stay, isolation, and fear of spreading the virus to others [12].

On multivariate analysis, the main factors explaining pulmonary functional outcomes were MV and ICU severity score at admission that reflect more severe illness. Several studies have focused on ICU mortality rate and management differences between waves. Carbonell et al. reported, as in the present series, an increased use of GC in w2/3 vs w1 [13]. The need for MV remained high in the three waves but an increased use of high-flow nasal oxygen (HFNO) was described that was not observed in our survivors. In their study, mortality was similar during the first three consecutive waves, whereas it decreased significantly in our series. In a Swiss study comparing short-term outcomes of hospitalized patients during the first and second waves, mortality was also similar despite the use of GC in 76\% vs 0\% [14]. Length of stay was shorter by 2.5 days in w2, as observed in our series for w3 vs w1 (-11 days).

Our study particularly focused only on long-term outcomes in ICU COVID-19 survivors and not on the characteristics of survivors versus non-survivors. Outcomes in hospitalized, including ICU, patient cohorts from w1 at 3 months and 4 months are now well documented [10,15-17], showing alterations in PFT (restrictive +/- decreased DLCO) and 6MWDT in about half of the patients, radiologic impairment in more than $70 \%$ of patients, and dyspnea in one-third. Radiologic abnormalities have been correlated with length of MV [15], length of ICU stay [16], initial radiologic extension [10], ICU admission and MV [17]. However, no studies have compared the outcomes of hospitalized patients according to successive pandemic waves.

It is surprising and disappointing that increased experience and use of effective medications in critically-ill patients since the mid-first wave did not change outcomes in survivors, despite a proven impact on 28-day mortality for GC [5], tocilizumab, and remdesevir, when given at the right time in the right patient $[18,19]$.

Mechanical ventilation is still a factor related to poor outcome 3 months after discharge, regardless of pandemic wave. MV has been reported as a major risk factor for death in COVID in two European studies [13,20], but when they survive, patients are also more disabled after MV. Impaired DLCO and 6MWDT have been shown to be related to MV in a Spanish series of 78

Page $8 / 11$ 
COVID-19 ICU patients [21]. Noel-Savina et al., in a French cohort of 72 patients that included 75\% ICU COVID-19 patients, also showed that COVID-19 patients who required MV exhibited more frequently impaired DLCO, gas exchange abnormalities, and interstitial lung disease on chest CT scan 4 months after discharge [17].

\section{Limitations}

Despite the relatively small sample size of our study, our results appear to correctly reflect the outcomes of the critically-ill COVID-19 population, as patient characteristics and management in this study were similar to other larger series $[13,14,17]$.

\section{Conclusions}

The present study shows, for the first time, a comparison of pulmonary functional outcomes, radiologic impairment, and quality of life 3 months after ICU discharge in critically-ill COVID-19 patients in the three waves of the COVID-19 pandemic. Disappointingly, despite increased experience and the use of more effective medications since the mid-first wave of COVID-19, PFT, 6MWDT, RMS, and chest CT alterations remained similar in ICU survivors, regardless of the wave of the pandemic in which they were hospitalized. QoL was decreased in w1 vs w3, probably related to the extreme fear observed at the beginning of the pandemic.

\section{Declarations}

Acknowledgements: The authors acknowledge the contribution of a medical writer, Sandy Field, PhD, for English language editing and formatting of the manuscript.

Author contributions: $C D, J S, S A, M B, M C, A R, A C, D D B, N D V$ collected the data; SA, CD, AVB, OM, SAl, MB,DDB,NDV performed data analyses and prepared the manuscript. SA, AC, JS, CD, AVB, OM, SAI, MB, DDB, NDV, MC, AR have approved the final version of the manuscript.

Funding: No funding was received to perform this study.

Availability of data and materials: The datasets used and analyzed during the current study are available from the corresponding author on reasonable request.

Ethics approval and consent to participate: All included patients provided written informed consent to participate in the study. The study protocol was approved by the Saint-Pierre University Hospital ethics committee (AK/16-01-18/4613) and by the Brugmann University Hospital ethics committee (CE2020/141).

\section{Consent for publication: Not applicable}

Competing interests: The authors certify that they have no affiliations with or involvement in any organization or entity with any financial interest (such as honoraria; educational grants; participation in speakers' bureaus; membership, employment, consultancies, stock ownership, or other equity interest; and expert testimony or patent-licensing arrangements), or nonfinancial interest (such as personal or professional relationships, affiliations, knowledge or beliefs) in the subject matter or materials discussed in this manuscript.

\section{References}

1. WHO Coronavirus COVID-19 Dashboard. https://covid19.who.int/. Accessed 21 February 2022.

2. European Centre for Disease Prevention and Control. COVID-19 Vaccine Tracker. https://vaccinetracker.ecdc.europa.eu/public/extensions/COVID-19/vaccine-tracker.html\#uptake-tab. Accessed 21 February 2022. 
3. ARDS Definition Task Force, Ranieri VM, Rubenfeld GD, Thompson BT, Ferguson ND, Caldwell E, Fan E, Camporota L, Slutsky AS. Acute respiratory distress syndrome: the Berlin Definition. JAMA 2012;307:2526-33. doi:

10.1001/jama.2012.5669.

4. Boban M. Novel coronavirus disease (COVID-19) update on epidemiology, pathogenicity, clinical course and treatments. Int J Clin Pract. 2021;75:e13868. doi: 10.1111/ijcp.13868.

5. RECOVERY Collaborative Group, Horby P, Lim WS, Emberson JR, Mafham M, Bell JL, Linsell L, Staplin N, Brightling C, Ustianowski A, et al. Dexamethasone in Hospitalized Patients with Covid-19. N Engl J Med. 2021;384:693-704. doi: 10.1056/NEJMoa2021436.

6. Wendel Garcia PD, Aguirre-Bermeo H, Buehler PK, Alfaro-Farias M, Yuen B, David S, Tschoellitsch T, Wengenmayer T, Korsos A, Fogagnolo A, et al. Implications of early respiratory support strategies on disease progression in critical COVID19: a matched subanalysis of the prospective RISC-19-ICU cohort. Crit Care. 2021;25:175. doi: 10.1186/s13054-021-03580y.

7. Nakamura ZM, Nash RP, Laughon SL, Rosenstein DL. Neuropsychiatric Complications of COVID-19. Curr Psychiatry Rep. 2021;23:25. doi: 10.1007/s11920-021-01237-9.

8. Zheng KI, Feng G, Liu WY, Targher G, Byrne CD, Zheng MH. Extrapulmonary complications of COVID-19: A multisystem disease? J Med Virol. 2021;93:323-35. doi:10.1002/jmv.26294.

9. Vrettou CS, Mantziou V, Vassiliou AG, Orfanos SE, Kotanidou A, Dimopoulou I. Post-Intensive Care Syndrome in Survivors from Critical Illness including COVID-19 Patients: A Narrative Review. Life (Basel). 2022;12:107. doi:

10.3390/life12010107.Truffaut L, Demey L, Bruyneel AV, Roman A, Alard S, De Vos N, Bruyneel M. Post-discharge critical COVID-19 lung function related to severity of radiologic lung involvement at admission. Respir Res. 2021;22:29. doi:

10.1186/s12931-021-01625-y.

10. Klok FA, Boon GJAM, Barco S, Endres M, Geelhoed JJM, Knauss S, Rezek SA, Spruit MA, Vehreschild J, Siegerink B. The Post-COVID-19 Functional Status scale: a tool to measure functional status over time after COVID-19. Eur Respir J. 2020;56:2001494. doi: 10.1183/13993003.01494-2020.

11. Hosey MM, Needham DM. Survivorship after COVID-19 ICU stay. Nat Rev Dis Primers. 2020;6:60.

12. Carbonell R, Urgelés S, Rodríguez A, Bodí M, Martín-Loeches I, Solé-Violán J, Díaz E, Gómez J, Trefler S, Vallverdú M, et al. Mortality comparison between the first and second/third waves among 3,795 critical COVID-19 patients with pneumonia admitted to the ICU: A multicentre retrospective cohort study. Lancet Reg Health Eur. 2021;11:100243. doi:

10.1016/j.lanepe.2021.100243.

13. Wolfisberg S, Gregoriano C, Struja T, Kutz A, Koch D, Bernasconi L, Hammerer-Lercher A, Mohr C, Haubitz S, Conen A, et al. Comparison of characteristics, predictors and outcomes between the first and second COVID-19 waves in a tertiary care centre in Switzerland: an observational analysis. Swiss Med Wkly. 2021;151:w20569. doi: 10.4414/smw.2021.20569.

14. González J, Benítez ID, Carmona P, Santisteve S, Monge A, Moncusí-Moix A, Gort-Paniello C, Pinilla L, Carratalá A, Zuil M, et al. Pulmonary Function and Radiologic Features in Survivors of Critical COVID-19: A 3-Month Prospective Cohort. Chest. 2021;160:187-98. doi: 10.1016/j.chest.2021.02.062.

15. Froidure A, Mahsouli A, Liistro G, De Greef J, Belkhir L, Gérard L, Bertrand A, Koenig S, Pothen L, Yildiz H, et al. Integrative respiratory follow-up of severe COVID-19 reveals common functional and lung imaging sequelae. Respir Med.

2021;181:106383. doi: 10.1016/j.rmed.2021.106383.

16. Noel-Savina E, Viatgé T, Faviez G, Lepage B, Mhanna LT, Pontier S, Dupuis M, Collot S, Thomas P, Idoate Lacasia J, et al. Severe SARS-CoV-2 pneumonia: Clinical, functional and imaging outcomes at 4 months. Respir Med Res. 2021;80:100822. doi: 10.1016/j.resmer.2021.100822.

17. Klopfenstein T, Gendrin V, Kadiane-Oussou NJ, Conrozier T, Zayet S; HNF Hospital Tocilizumab Multidisciplinary Team. Tocilizumab in COVID-19 pneumonia: Practical proposals based on a narrative review of randomised trials. Rev Med Virol. 2022;32:e2239. doi: 10.1002/rmv.2239.

18. Angamo MT, Mohammed MA, Peterson GM. Efficacy and safety of remdesivir in hospitalised COVID-19 patients: a systematic review and meta-analysis. Infection. 2022;50:27-41. doi: 10.1007/s15010-021-01671-0. 
19. Domingo P, Pomar V, Mur I, Castellví I, Corominas H, de Benito N. Not all COVID-19 pandemic waves are alike. Clin Microbiol Infect. 2021;27:1040.e7-

1040.e10

. doi: 10.1016/j.cmi.2021.04.005.

20. Cabo-Gambin R, Benítez ID, Carmona P, Santiesteve S, Minguez O, Vaca R, Moncusí-Moix A, Gort-Paniello C, García-Hidalgo MC, de Gonzalo-Calvo D, et al. Three to Six Months Evolution of Pulmonary Function and Radiological Features in Critical COVID-19 Patients: A Prospective Cohort. Arch Bronconeumol (Engl Ed). 2021 Jul 27. doi: 10.1016/j.arbres.2021.07.005.

\section{Figures}

\section{COVID-19 ICU admission 3 waves, $n=567$}

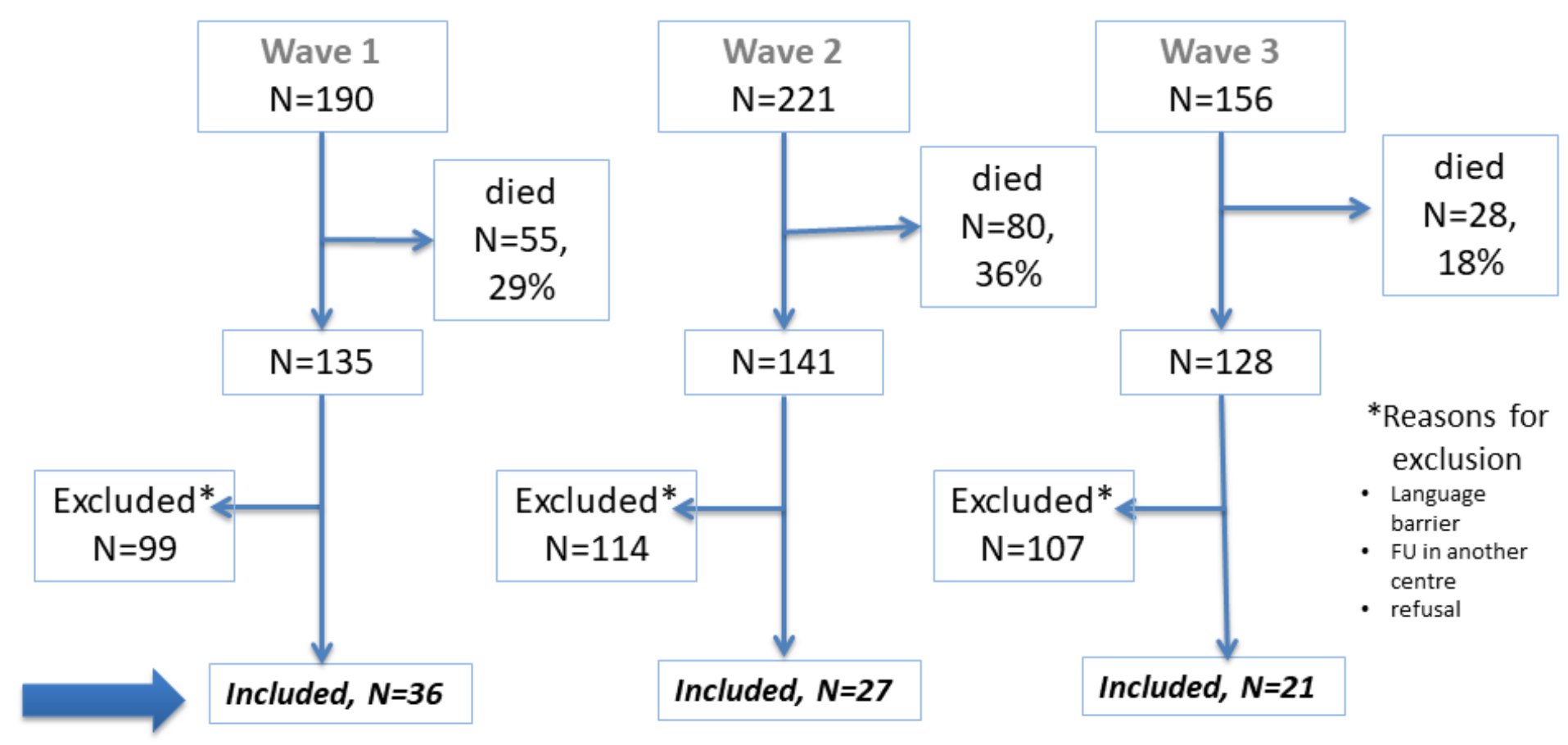

Figure 1

Flow chart of patients included in the study 